nated histoplasmosis by detection of Histoplasm capsulatum antigen in serum and urine specimens. $\mathrm{N}$ Engl J Med 1986;314:83-8.

3. Dines DE, Payne WS, Bernatz PE, Pairolero PC. Mediastinal granuloma and fibrosing mediastinitis. Chest 1979;75:320-4.

4. Coss KC, Wheat LJ, Conces DJ, Brashear RE, Hull MT.
Esophageal fistula complicating mediastinal histoplasmosis. Am J Med 1987;83:343-6.

5. Forsmark CE, Wilcox CM, Darragh TM, et al. Disseminated histoplasmosis in ADS: an unusual case of esophageal in volvement and gastrointestinal bleeding. Gastrointest Endosc 1990;36:604-5.

\title{
UPPER AIRWAY OBSTRUCTION CAUSED BY LOW-GRADE TRACHEAL PAPILLARY ADENOCARCINOMA: AN UNUSUAL FLOW-VOLUME LOOP PATTERN
}

\author{
David E. Clarke, MD, ${ }^{a}$ Ronald J. Green, MD, James B. D. Mark, MD, ${ }^{\mathrm{b}}$ Robert C. Robbins, MD, ${ }^{\mathrm{b}}$ and
}

Thomas A. Raffin, MD, ${ }^{\text {a }}$ Stanford, Calif.

Tumors obstructing the upper airway often masquerade as asthma before definitive diagnosis. ${ }^{1}$ As initially described by Miller and Hyatt, ${ }^{2}$ flow-volume loops in patients with these obstructing lesions demonstrate characteristic patterns, depending on tumor location (extrathoracic or intrathoracic) and type (fixed or variable obstruction). We describe the case of a woman admitted for control of asthma who was found to have an unusual flow-volume loop pattern. Her flow-volume loop was different from previously described patterns of intrathoracic upper airway obstruction. Recognition of the different flow-volume loop patterns produced by upper airway obstruction is essential for early diagnosis and treatment of this potentially life-threatening problem.

Case report. A 60-year-old woman was brought to Stanford University Hospital with shortness of breath. She described paroxysms of dyspnea, often precipitated by coughing, that had occurred during the previous 4 to 5 months. In most instances, the shortness of breath lasted only a few minutes. The patient described the sensation as, "A cap went over my windpipe." She had sought medical advice from many different physicians, most of whom said she had asthma, and she had been using an albuterol inhaler intermittently for a 4-month period. Two weeks before admission, she was referred to a pulmonologist, who concurred with the diagnosis of asthma and prednisone was prescribed at a dosage of 60 mg per day. On the day of admission, she had a severe episode of shortness of breath and was brought to the emergency department by ambulance. She was a lifelong nonsmoker. She had drunk significant quantities of alcohol in her youth but none since.

From the Divisions of Pulmonary and Critical Care Medicine ${ }^{a}$ and the Division of Thoracic Surgery, ${ }^{b}$ Stanford University School of Medicine, Stanford, Calif.

Received for publication July 21, 1995; accepted for publication August 28, 1995.

J Thorac Cardiovase Surg 1996;111:1286-8

Copyright (C) 1996 by Mosby-Year Book, Inc.

$0022-5223 / 96 \$ 5.00+0 \quad \mathbf{1 2 / 5 4 / 6 8 9 1 8}$
At admission physical examination, the patient was breathing comfortably after a nebulized albuterol treatment. Results of head and neck examination were normal. Her breath sounds were clear. With a forced vital capacity maneuver, the patient could exhale for only a brief period before all air movement ceased. She had no difficulty, however, with quiet breathing. She had a grade II/VI systolic ejection murmur, and the remainder of her examination was unremarkable. An arterial blood gas analysis done on admission to the emergency department revealed a $\mathrm{pH}$ of 7.39 , carbon dioxide tension of $49 \mathrm{~mm} \mathrm{Hg}$, and an oxygen tension of $98 \mathrm{~mm} \mathrm{Hg}$ with the patient breathing $60 \%$ oxygen by face mask. One hour later, while she was breathing room air, her oxygen saturation was $98 \%$. She had a leukocyte count of 20,100 cells $/ \mathrm{mm}^{3}$, with 82 polymorphonuclear leukocytes, 8 band cells, and 10 lymphocytes. Lactate dehydrogenase level was 792 IU/L (normal 313 to $618 \mathrm{IU} / \mathrm{L}$ ); the remainder of her complete blood cell count and chemistry panel results were normal. A chest radiograph was normal.

The patient was admitted to the hospital and given nebulized albuterol and prednisone. Pulmonary function tests were performed. The flow-volume loop was remarkable, demonstrating an immediate cutoff of forced expiratory flow (Fig. 1, $A$ ). The expiratory loop was reminiscent of extremely severe emphysema, except that pulmonary function tests revealed a normal slow vital capacity. The differential diagnosis included upper airway obstruction and vocal cord dysfunction mimicking asthma. Results of otolaryngologic evaluation by fiberoptic laryngoscopy to the level of the vocal cords were normal. At fiberoptic bronchoscopy, a large mass was observed at the main carina. This mass appeared to be attached to the trachea by a stalk, and it prolapsed in and out of the left main stem bronchus during respiratory movements. The next day, because the mass nearly occluded the trachea, it was severed with a laser and removed by means of rigid bronchoscopy. The patient tolerated the procedure well, and her condition was markedly improved after she awakened from anesthesia. Pathologic examination of the mass revealed it to be a low-grade papillary adenocarcinoma with negative 


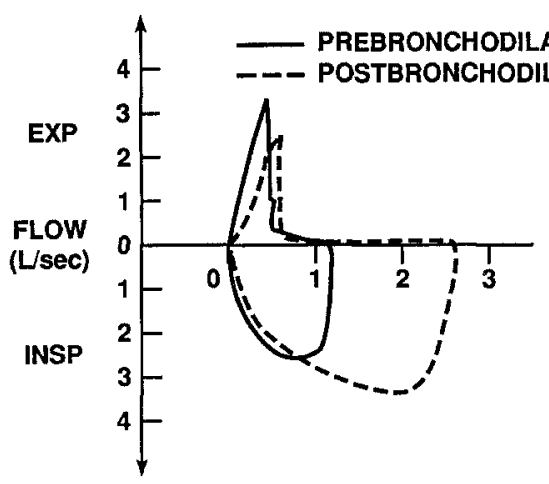

A

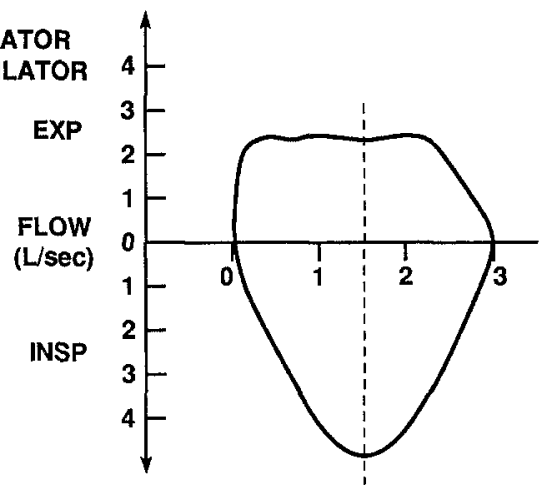

B

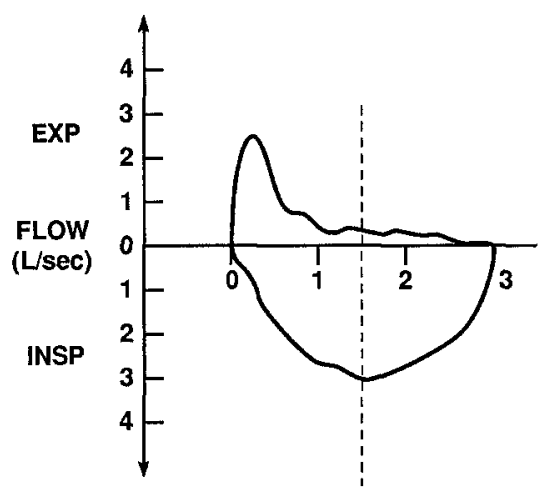

C

Fig. 1. A, Flow-volume loop of 60 -year-old woman with "asthma syndrome." There is a sharp cutoff of the expiratory limb, a pattern suggestive of pulmonary emphysema. Bronchodilators increased the size of the inspiratory limb. INSP, Inspiratory; $E X P$, expiratory. B, Classic pattern of expiratory plateauing as a result of variable intrathoracic upper airway obstruction as described by Miller and Hyatt. (From: Miller RD, Hyatt RE. Obstructing lesions of the larynx and trachea: clinical and physiologic characteristics. Mayo Clin Proc 1969;44:152. Reproduced with permission.) C, Flow-volume loop from 1976 report of patient with adenocystic basal cell carcinoma of the trachea in whom the flow rate did not rapidly fall to zero (compare with A). (From: Kryger M, Boide J, Antic R, Anthonisen N. Diagnosis of obstruction of the upper and central airways. Am J Med 1976;61:90. Reprinted with permission from American Journal of Medicine.)

staining for thyroglobulin. Bronchoscopy 1 year later demonstrated no evidence of recurrence.

Discussion. The flow-volume loop pattern in this case was not characteristic of the expiratory plateau pattern resulting from variable intrathoracic obstruction described by Miller and Hyatt ${ }^{2}$ (Fig. 1, B). This patient's expiratory flow velocity reached zero very quickly, a pattern not previously reported in the literature. ${ }^{2-5}$ In 1976, a review of upper and lower airway obstruction described a woman with an adenocystic basal cell carcinoma of the trachea whose flow-volume curves suggested a lesion that was causing variable intrathoracic obstruction. ${ }^{1}$ Her expiratory flow was stated to oscillate between low lung volumes and zero, but the flow-volume loop depicted in the case history did not demonstrate a flow rate rapidly falling to zero (Fig. 1, C). As seen in flow-volume loops of patients with variable intrathoracic obstruction, ${ }^{3,5}$ our patient's maximal inspiratory flow at $50 \%$ of vital capacity was greater than her maximal expiratory flow at $50 \%$ of vital capacity. Our patient had an excellent response to bronchodilators (forced vital capacity and forced expiratory volume in 1 second improved by $108 \%$ and $79 \%$, respectively), however, in contrast to previous studies reporting lack of response to bronchodilators as an important determinant in the diagnosis of obstructing intrathoracic lesions. ${ }^{4}$

Tracheal tumors are not common. ${ }^{6}$ Early symptoms generally suggest the diagnosis of obstructive airway disease. ${ }^{1}$ Interestingly, patients themselves may perceive their problem accurately, as in the case of our patient, who stated, "A cap went over my windpipe" or those of others, who have reported "closing of the windpipe."1
The distinctive pattern of the flow-volume loop observed in our patient was probably caused by two factors. First, the large size of the mass (approximately $3 \times 2 \times 1$ $\mathrm{cm}$ ) probably occluded the trachea during forced expiration. Second, the stalk of the tumor allowed it to travel from the left main stem bronchus into the trachea.

This is the first reported case of low-grade papillary adenocarcinoma involving the distal trachea. These tumors are uncommon, indolent, slow-growing tumors that are most often seen in the nasopharynx. ${ }^{7}$ They are easily differentiated from metastatic thyroid papillary carcinoma by their appearance under light microscopy and negative staining for thyroglobulin. ${ }^{7}$ Surgical excision is the definitive treatment. In the largest reported series of low-grade nasopharyngeal papillary adenocarcinoma (nine cases), ${ }^{7}$ all patients remained free of disease after a median follow-up of 6.75 years after surgical resection.

Several salient features of this case merit emphasis. First, although asthma is a common cause of dyspnea, it rarely gives patients the sensation of something "closing the windpipe." Second, pulmonary function testing is an invaluable tool in the diagnosis of airway disease. Third, our patient's flow-volume loop pattern in this clinical setting was potential evidence of an intrathoracic lesion variably obstructing the upper airway. Finally, surgical excision is the treatment of choice for low-grade papillary adenocarcinoma.

\section{REFERENCES}

1. Kryger M, Boide J, Antic R, Anthonisen N. Diagnosis of obstruction of the upper and central airways. Am J Med 1976;61:85-93. 
2. Miller RD, Hyatt RE. Obstructing lesions of the larynx and trachea: clinical and physiologic characteristics. Mayo Clin Proc 1969;44:145-61.

3. Gamsu G, Borson DB, Webb WR, Cunningham JH. Structure and function in tracheal stenosis. Am Rev Respir Dis 1980;121:519-31.

4. Miller WF, Scacci R, Gast LR. Laboratory evaluation of pulmonary function. Philadelphia: JB Lippincott, 1987.

5. Miller RD, Hyatt RE. Evaluation of obstructing lesions of the trachea and larynx by flow-volume loops. Am Rev Respir Dis 1973;108:475-81.

6. Baumgartrier WA, Mark JB. Metastatic malignancies from distant sites to the tracheobronchial tree. J Thorac Cardiovasc Surg 1980;79:499-503.

7. Wenig BM, Hyams VJ, Heffner DK. Nasopharyngeal papillary adenocarcinoma: a clinicopathologic study of a low-grade carcinoma. Am J Surg Pathol 1988;12:946-53. 